\title{
Produtividade de quiabeiro sob influência de diferentes doses de esterco bovino
}

Uma das opções para os pequenos agricultores perante o aumento dos custos dos fertilizantes minerais e a crescente poluição ambiental é o uso dos adubos orgânicos, que vem se tornando uma saída economicamente atrativa, tornando útil o uso de estercos que normalmente eram descartados na propriedade passando a fazer uso desse material com intuito de melhorar as características químicas, físicas e biológicas do solo e consequentemente aumentos nas taxas de produtividade. Objetiva-se com a pesquisa avaliar diferentes doses de esterco bovino na produtividade da cultura do quiabeiro. Visto que o uso $O$ experimento fo desenvolvido no Centro de Ciências Agrárias e Ambientais - CCAA, da Universidade Federal do Maranhão- UFMA, no município de Chapadinha- MA, com delineamento experimental em blocos casualizados, com seis tratamentos (0, 20,30, 40, 50 tha de esterco bovino e um tratamento com adubação mineral) com quatro repetições. Foram realizadas avaliações do número de frutos por planta, massa média dos frutos frescos, comprimento dos frutos, diâmetro dos frutos, altura da planta e produtividade de frutos com a adubação mineral. A dosagem de 50 t ha-1 de esterco bovino proporcionou os melhores resultados na produtividade, responsável por 1,951 t ha-1 de frutos de quiabos. Nas condições edafoclimáticas do presente estudo a adubação de utilizando o esterco bovino proporciona bom incremento na produtividade do quiabeiro.

Palavras-chave: Abelmoschus esculentus (L.); Orgânico; Resíduo animal; Latossolo Amarelo distrófico.

\section{Productivity of okra under the influence of different doses of bovine manure}

\begin{abstract}
One of the options for small farmers in the face of rising mineral fertilizer costs and increasing environmental pollution is the use of organic fertilizers, which has become an economically attractive outlet, making use of manure normally disposed of on the property to make use of this material in order to improve the chemical, physical and biological characteristics of the soil and consequently increases in productivity rates. In view of the above, the objective was to evaluate different doses of cattle manure in the productivity of the okra culture. The experiment was carried out at the Agricultural and Environmental Sciences Center (CCAA) of the Federal University of Maranhão, UFMA, in the municipality of Chapadinha, Brazil, with a randomized complete block design with six treatments $(0$, $20,30,40,50$ tha of bovine manure and a treatment with mineral fertilization) with four replicates. Evaluations were performed on the number of fruits per plant average fresh fruit mass, fruit length, plant height and fruit yield with mineral fertilization. The $50 \mathrm{tha}-1$ dosage of bovine manure provided the best yield results, accounting for 1,95 tha-1 of okra fruits. In the edaphoclimatic conditions of the present study, fertilization using bovine manure provides a good increase in the yield of okra.
\end{abstract}

Keywords: Abelmoschus esculentus (L.); Arganic; Animal waste; Dystrophic Yellow Latosol.

Topic: Agroecologia

Reviewed anonymously in the process of blind peer
Received: $02 / 12 / 2020$

Approved: $\mathbf{2 3 / 1 2 / 2 0 2 0}$
Sâmia dos Santos Matos (iD

Universidade Federal do Piauí, Brasil http://lattes.cnpq.br/0156452279835438

http://orcid.org/0000-0002-4573-9277

samiamatos2011@hotmail.com

Romário Martins Costa (id

Universidade Federal do Piauí, Brasil

http://lattes.cnpq.br/8193853986166353

http://orcid.org/0000-0001-5429-4663

romario.martins90@hotmail.com

Rayssa Carolinne Mouzinho de Sousa (iD) Universidade Federal do Piauí, Brasil

http://lattes.cnpq.br/6135660736968929

http://orcid.org/0000-0002-1478-872X

rayssamouzinho@gmail.com

Marcos Renan Lima Leite
Universidade Federal do Piauí, Brasil
http://lattes.cnpq.br/7363525329923328
$\begin{aligned} & \text { http://orcid.org/0000-0002-2910-9232 } \\ & \text { marcos_Ileite@hotmail.com }\end{aligned}$
Mariléia Barros Furtado (DD
Universidade Federal do Piauí, Brasil
http://lattes.cnpq.br/0177700018215014
http://orcid.org/0000-0003-4696-2136
marileiafurtado@hotmail.com
Maryzélia Furtado de Farias @D
Universidade Federal do Piauí, Brasil
http://lattes.cnpq.br/2230366525752958
http://orcid.org/0000-0001-9078-1354
maryzelia@ig.com.br

uisa Julieth Parra Serrano (10) Universidade Federal do Piauí, Brasil http://lattes.cnpq.br/6001864868903542 http://orcid.org/0000-0002-9796-1988 julieth_ps@yahoo.com
Referencing this:

MATOS, S. S.; COSTA, R. M.; SOUSA, R. C. M.; LEITE, M. R. L.; FURTADO, M. B.; FARIAS, M. F.; SERRANO, L. J. P.. Produtividade de quiabeiro sob influência de diferentes doses de esterco bovino. Revista Ibero Americana de Ciências Ambientais, v.11, n.7, p.137144, 2020. DOI: http://doi.org/10.6008/CBPC21796858.2020 .007 .0012 


\section{INTRODUÇÃO}

O quiabeiro (Abelmoschus esculentus (L.) Moench) é uma olerácea de grande relevância da família das Malváceas. É uma hortaliça fruto anual originária do continente africano, e introduzida no Brasil pelos escravos. É uma planta típica de clima quente, exigente em temperaturas que variam entre 18,3 e $35{ }^{\circ} \mathrm{C}$ (FILGUEIRA, 2008).

O Brasil tem uma produção de 116.190 t de quiabo, sendo as regiões Nordeste e Sudeste as maiores produtoras. O estado de Minas Gerais se destaca como o maior produtor nacional com 27.754 t. No Nordeste o Maranhão tem a terceira maior produção com $6.012 \mathrm{t}$, atrás somente dos estados de Pernambuco e da Bahia (IBGE, 2006).

Embora não seja uma das hortaliças preferidas pela população brasileira, o interesse pelo seu consumo vem crescendo, principalmente devido a sua importância nutricional. Através do consumo do fruto é possível ingerir vitaminas $A, C$ e B1, além de cálcio, mineral essencial para o fortalecimento dos ossos (SABITHA et al., 2011). É rico em ácido fólico, tiamina, caroteno, riboflavina, niacina, baixa gordura saturada e colesterol (SOUSA et al., 2015).

O quiabeiro apresenta algumas características desejadas pelos agricultores, como alta rusticidade, resistência ao calor, ciclo curto e é vista como uma cultura que possui grandes chances de aumento da sua produção, à qual é advinda basicamente dos pequenos produtores (OLIVEIRA et al., 2003). É cultivada em 28.367 propriedades agrícolas em todo o Brasil, porém, com reduzida tecnologia (TIVELLI et al., 2013), principalmente quando se trata de adubação mineral, haja vista que é utilizada em apenas $15,9 \%$ das unidades de produção recenseadas, devido principalmente aos seus altos custos (IBGE, 2006).

Na produção há um destaque para a variedade Santa Cruz 47, que é largamente cultivada no Brasil, devido aos seus vários diferenciais, como a alta produtividade e a excelente uniformidade de plantas e frutos (SOUZA et al., 2014).

Uma das opções para os pequenos agricultores perante o aumento do preço dos fertilizantes minerais e a crescente poluição ambiental é o uso dos adubos orgânicos, que vem se tornando uma saída economicamente atrativa, tornando útil o uso de estercos que normalmente eram descartados na propriedade, passando a fazer uso desse material com o intuito de melhorar as características químicas, físicas e biológicas do solo (BASSO et al., 2008).

O esterco bovino é uma fonte de nutrientes muito utilizada, devido especialmente à preocupação com a produção sustentável e aos efeitos positivos nas propriedades físicas e biológicas do solo, tendo como consequência a elevação na produtividade das culturas (OLIVEIRA et al., 2010).

O esterco bovino tem efeitos positivos nas características químicas do solo, fornece principalmente N, K, Ca, Mg, eleva a CTC (Capacidade de troca catiônica) e a saturação por bases, aumenta o potencial de mineralização e a disponibilidade de nutrientes às plantas (ARAUJO et al., 2008).

Diversos autores vêm buscando respostas sobre os efeitos do uso do esterco bovino na adubação de várias culturas. De acordo com Linhares et al. (2015) o esterco bovino proporcionou rendimentos máximos 
de 6,453 e t ha-1 de massa verde de coentro, com a dose de $60 \mathrm{t} \mathrm{ha}^{-1}$. Esse resultado aponta que as necessidades nutricionais do coentro podem ser supridas com a adubação orgânica. Oliveira et al. (2003) identificaram a eficiência do esterco bovino na massa média dos frutos de quiabo com $16,5 \mathrm{~g}$, com aplicação de $60 \mathrm{t} \mathrm{ha}^{-1}$ de esterco bovino.

No entanto, para que a adubação seja eficaz e correta do ponto de vista ambiental é necessário conhecer a espécie do animal, idade, alimentação e principalmente da dosagem a ser aplicada (KHATOUNIAN, 2001). Dosagens muito baixas podem levar a deficiência de nutrientes e baixos rendimentos. Por outro lado, uma taxa muito alta pode levar à lixiviação de nitratos, escoamento de fósforo, por isso há a necessidade de estudos para que as dosagens corretas sejam definidas (PEIXOTO FILHO et al., 2013).

Os agricultores da região de Chapadinha enfrentam alguns problemas na produção do quiabo, em que um deles é o alto preço dos fertilizantes minerais, fato que a maioria das vezes impossibilita o uso nas lavouras, resultando em baixas produtividades. Uma alternativa viável para os pequenos agricultores é a utilização dos recursos encontrados na propriedade rural, de forma a elevar a produtividade é incrementar o lucro da produção. Diante do exposto objetiva-se avaliar diferentes doses de esterco bovino na produtividade da cultura do quiabeiro.

\section{MATERIAIS E MÉTODOS}

O experimento foi desenvolvido no Centro de Ciências Agrárias e Ambientais - CCAA, da Universidade Federal do Maranhão - UFMA, no município de Chapadinha - MA (0344'28,7"S e 4318'46"W e altitude de $105 \mathrm{~m}$ ), no período de janeiro a abril de 2018. O clima da região é caracterizado como equatorial quenteúmido, com temperatura média anual $26.9{ }^{\circ} \mathrm{C}$ e pluviosidade média anual de $1670 \mathrm{~mm}$.

O solo da área experimental foi classificado como Latossolo Amarelo distrófico (SANTOS et al., 2013),

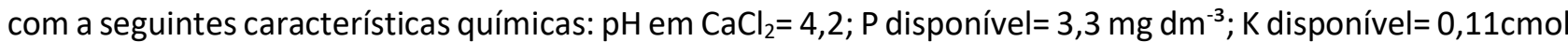
$\mathrm{dm}^{-3} ; \mathrm{Ca}+\mathrm{Mg}=1,36 \mathrm{cmol} \mathrm{dm}^{-3} ;$ matéria orgânica $=15,1 \mathrm{~g} \mathrm{Kg}^{-1} ; \mathrm{Al}=0,32 \mathrm{cmol} \mathrm{dm}^{-3} ; \mathrm{H}+\mathrm{Al}=3,05 \mathrm{cmol} \mathrm{dm}^{-3} ; \mathrm{SB}=$ $1,47 \mathrm{cmol} \mathrm{dm}^{-3} ; \mathrm{CTC}=4,52 \mathrm{cmol} \mathrm{dm}^{-3}$ e V\% $=32,5 \%$. A caracterização química do esterco bovino revelou a seguinte composição: $\mathrm{N}=14,3 \mathrm{~g} / \mathrm{kg} ; \mathrm{P}=3,98 \mathrm{~g} / \mathrm{kg} ; \mathrm{P}_{2} \mathrm{O}_{5}=9,11 \mathrm{~g} / \mathrm{kg} ; \mathrm{K}=57,9 \mathrm{~g} / \mathrm{kg} ; \mathrm{K}_{2} \mathrm{O}=70,72 \mathrm{~g} / \mathrm{kg} ; \mathrm{Ca}=6,86$ e $\mathrm{Mg}=20,6 \mathrm{~g} / \mathrm{kg}$.

Utilizou-se o delineamento experimental em blocos casualizados, com seis tratamentos $(0,20,30$, 40, $50 \mathrm{t} \mathrm{ha}^{-1}$ de esterco bovino e um tratamento com adubação mineral com quatro repetições. Cada parcela com uma superfície de $20 \mathrm{~m}^{2}$, com estande formado por 54 plantas e 10 plantas na área útil, espaçadas em $1,0 \mathrm{~m}$ entre fileiras e $0,50 \mathrm{~m}$ entre plantas.

No preparo da área foi realizada a aração e em seguida a gradagem. A calagem com calcário dolomítico com o poder relativo de neutralização (PRNT) 100\% ocorreu 30 dias antes da implantação da cultura com o intuito de elevar o índice de saturação por bases para 70 \%. A adubação com o esterco bovino foi realizada em sulcos 7 dias antes do plantio, e a adubação mineral foi efetuada de acordo com o resultado da análise de solo e seguindo as necessidades da cultura conforme as recomendações de Alvarez et al. (1999), aplicando no plantio $20 \%$ do nitrogênio $\left(24 \mathrm{~kg} \mathrm{ha}^{-1}\right), 40 \%$ do potássio $\left(72 \mathrm{~kg} \mathrm{ha}^{-1}\right)$ e todo o fósforo 
recomendado $\left(160 \mathrm{~kg} \mathrm{ha}^{-1}\right)$, e nas adubações de cobertura foi aplicado o restante do nitrogênio (80 \%) e do potássio (60 \%), parcelado em três vezes, aos 20, 40 e 60 dias após emergência das plântulas.

A instalação da cultura realizou-se por meio da semeadura direta da cultivar Santa Cruz 47, colocando-se 4 sementes por cova a $3 \mathrm{~cm}$ de profundidade. $\mathrm{O}$ desbaste foi efetuado quando as plantas apresentaram de 15 a $20 \mathrm{~cm}$ de comprimento, restando uma planta por cova. Para o controle das plantas daninhas, no decorrer do estudo foram realizadas 3 capinas.

Durante a condução do experimento foi realizado o controle de mosca branca (Bemisia ssp) e fumagina, e para o combate destas foram realizas três aplicações de extrato de folhas de nim indiano (Azadirachta indica A. Juss), três aplicações de calda de sabão e óleo e uma aplicação final com alho, cebola e sabão (ANDRADE et al., 2001).

As colheitas aconteceram entre os 70 e 90 dias após a semeadura, a cada 3 dias. Os frutos foram lavados, pesados, mensurados e avaliados no laboratório de Engenharia de Água e solos da instituição. As variáveis estudadas no trabalho foram: altura da planta, comprimento dos frutos, diâmetro dos frutos, número de frutos por planta, massa média dos frutos frescos e produtividade dos frutos.

Os dados foram submetidos ao teste de normalidade (Shapiro Wilk, $p<0,05$ ), e em seguida foi efetuada a análise de variância (ANOVA) por meio do software Infostat ${ }^{\circ}$ e realizada a decomposição dos graus de liberdade em contraste ortogonais para verificar os efeitos linear e quadrático, além da comparação de médias pelo teste de Duncan ao nível de $5 \%$ de probabilidade.

\section{RESULTADOS E DISCUSSÃO}

As doses de esterco bovino empregadas na produção do quiabeiro tiveram efeito significativo a $(\mathrm{P}<$ 0,05), para todas as variáveis estudadas.

A adubação com 50 t ha-1 propiciou o melhor desenvolvimento para altura da planta (Figura 1) de quiabeiro com média máxima de 105,28 cm, com 90 dias após emergência das plâtulas, esse resultado pode ser relacionado ao fato que na dose de $50 \mathrm{t} \mathrm{ha}^{-1}$ de esterco bovino faz-se presente a maior concentração de $\mathrm{N}$, nutriente que participa de processos como a fotossíntese, respiração, multiplicação e diferenciação celular consequentemente influenciando diretamente no crescimento da planta (TAIZ et al., 2004).

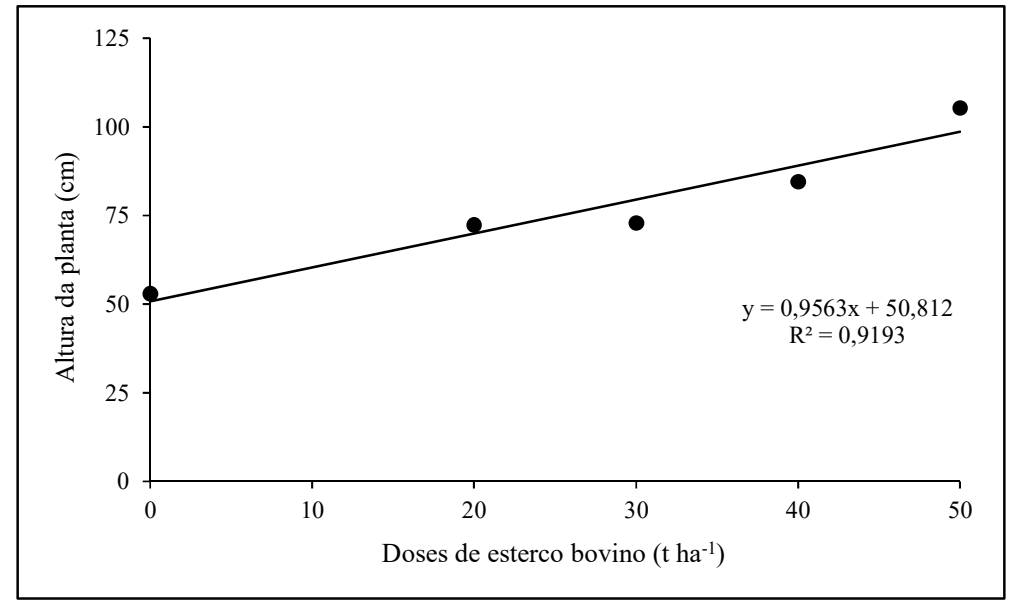

Figura 1: Altura da planta de quiabeiro da cultivar Santa Cruz em função de diferentes doses de esterco bovino. 
As médias do comprimento dos frutos se ajustaram ao modelo quadrático de regressão (Figura 2) onde pela derivada calculou-se a dose máxima de $39,26 \mathrm{t} \mathrm{ha}^{-1}$ de esterco bovino, como a responsável pelo maior comprimento $12,38 \mathrm{~cm}$ dos frutos.

Silva et al. (2012) estudando os componentes da produção do quiabeiro adubado com esterco bovino verificaram comprimento com média $13,3 \mathrm{~cm}$ para a dosagem de $40 \mathrm{t} \mathrm{ha}^{-1}$, próxima à encontrada no presente estudo. Esse resultado mostrou-se positivo, sendo que essa variável é muito importante, uma vez que são considerados frutos comerciais aqueles com comprimento entre 10 e $15 \mathrm{~cm}$ (FIGUEIRA, 2008).

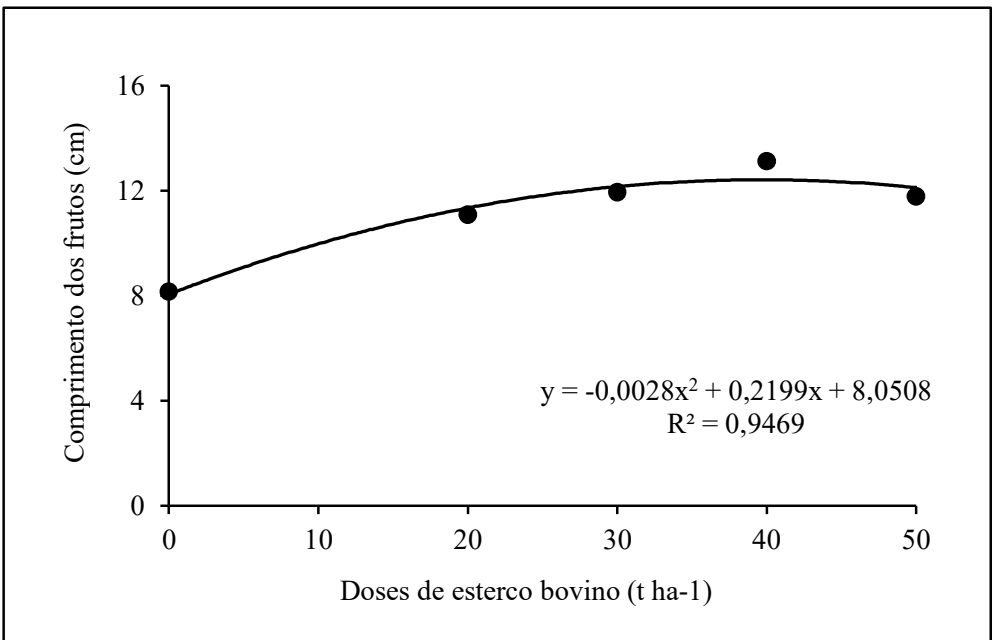

Figura 2: Comprimento dos frutos de quiabeiro da cultivar Santa Cruz em função de diferentes doses de esterco bovino.

Os resultados a cima estão possivelmente ligados as concentrações dos nutrientes N, P e K presentes no esterco bovino, favorecendo o desenvolvimento na multiplicação, alongamento das células e aumento do comprimento dos frutos (PES et al., 2015). O número de frutos por planta aumentou de forma linear de acordo com as doses de esterco bovino (Figura 3), obtendo como melhor resultado 5 frutos por planta com a aplicação da dosagem máxima $50 \mathrm{t} \mathrm{ha}{ }^{-1}$.

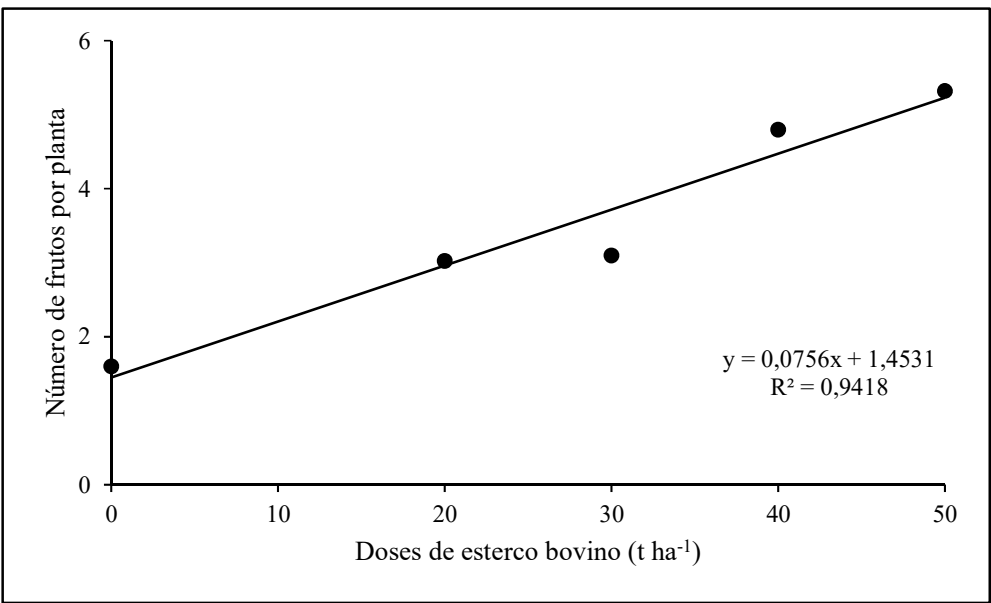

Figura 3: Número de frutos de quiabeiro da cultivar Santa Cruz em função de diferentes doses de esterco bovino.

A decorrência de 5 frutos por planta pode estar associada ao curto período de colheita (21 dias) devido à incidência da fumagina que recobriu as folhas, diminuindo a taxa fotossintética e 
consequentemente a produção de frutos.

Quanto a massa média dos frutos (Figura 4), os dados se ajustaram ao modelo de regressão linear, com máxima de 53, $25 \mathrm{~g}$ para a dosagem $50 \mathrm{t} \mathrm{ha}^{-1}$. Oliveira et al. (2003) identificaram a eficiência do esterco bovino na massa média dos frutos de quiabo com $16,5 \mathrm{~g}$, com aplicação de $60 \mathrm{t} \mathrm{ha}^{-1}$ de esterco bovino.

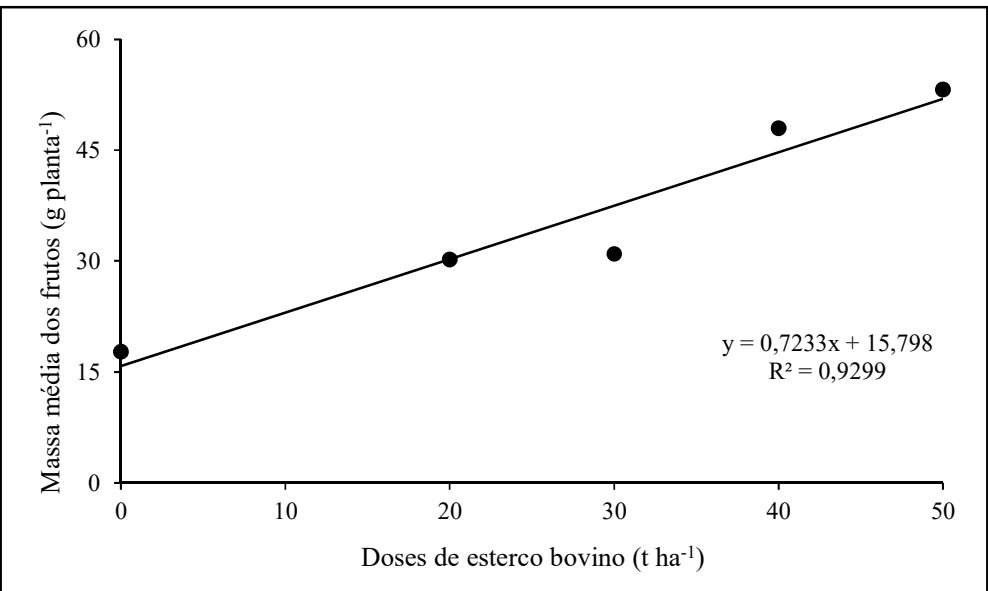

Figura 4: Massa média dos frutos de quiabeiro da cultivar Santa Cruz em função de diferentes doses de esterco bovino.

A produtividade dos frutos (Figura 5) teve um aumento linear de acordo com os acréscimos nas quantidades do esterco bovino. A maior produtividade obtida foi de $1,95 \mathrm{t} \mathrm{ha}{ }^{-1}$ de frutos de quiabo com a dosagem de $50 \mathrm{t} \mathrm{ha}^{-1}$.

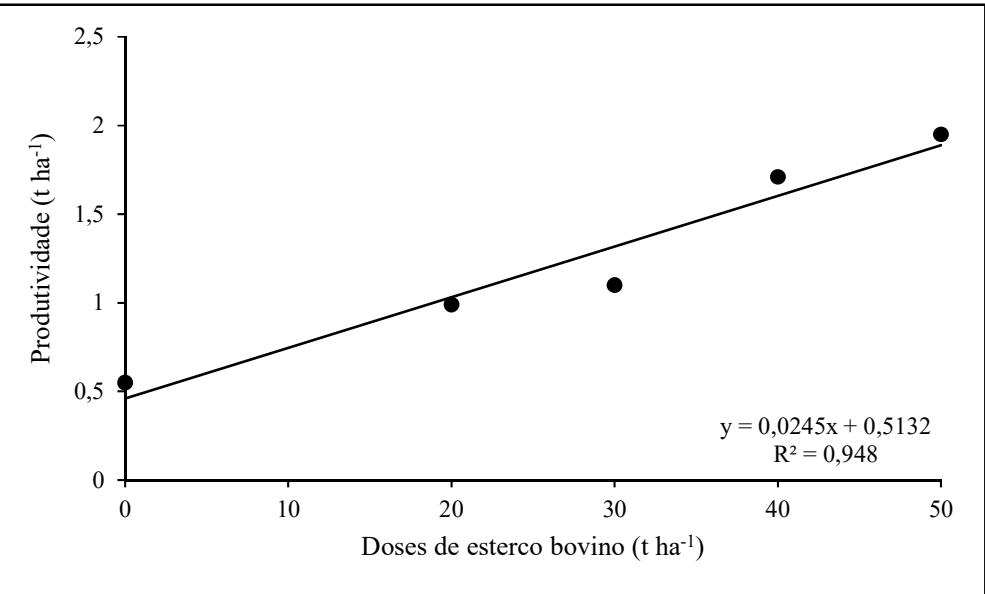

Figura 5: Produtividade dos frutos de quiabeiro da cultivar Santa Cruz em função de diferentes doses de esterco bovino.

O incremento no número, massa dos frutos e produtividade, está ligado à quantidade incorporada do esterco bovino, visto que a dosagem máxima $\left(50 \mathrm{t} \mathrm{ha}^{-1}\right)$ atendeu melhor a necessidade da cultura, isto pode ser interpretado como uma consequência da disposição dos macronutrientes presentes na sua composição, como N, P e K (ARAUJO et al., 2011; ARAUJO et al., 2008).

A aplicação de uma maior quantidade de esterco bovino contribuiu com o incremento no teor de matéria orgânica, contribuindo com as características físicas do solo, permitindo elevar a CTC , a macro e micro porosidade do solo, aumentando a retenção de água, gerando a formação de agregados que influencia na capacidade de infiltração, aeração, temperatura, redução na densidade do solo Favorendo a penetração 
das raízes, absorção dos nutrientes e consequentemente no crescimento e desenvolvimento das plantas (SANTOS et al., 2006; TRANI et al., 2008).

Ao comparar a produtividade obtida pela cultivar em função das dosagens de esterco bovino e a adubação mineral (Figura 6), foi possível verificar que não houve diferenças significativas entre os tratamentos com (30, 40 e $\left.50 \mathrm{t} \mathrm{ha}^{-1}\right)$ de esterco bovino e a adubação mineral.

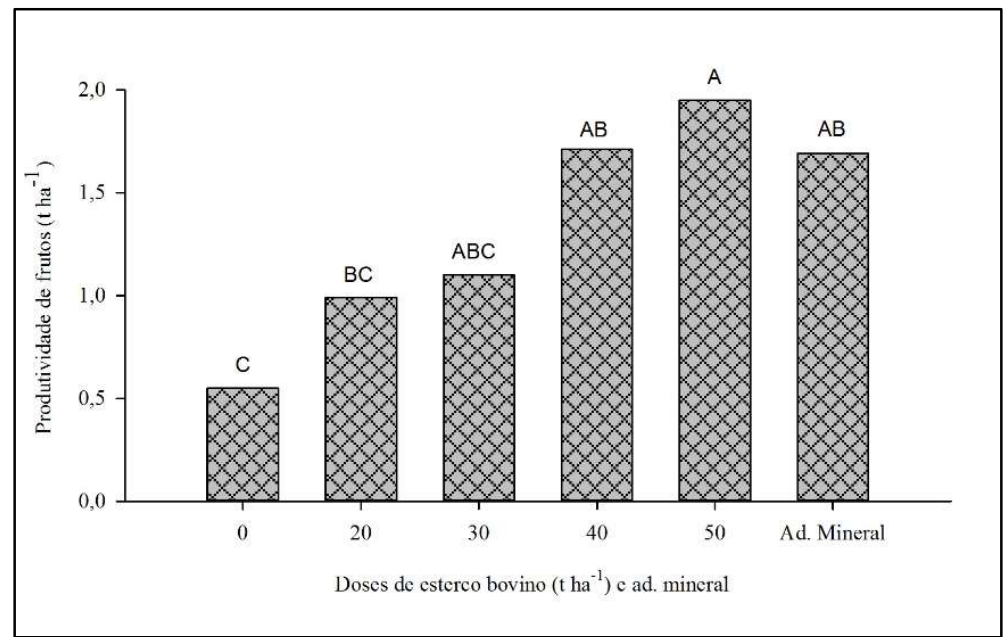

Figura 6: Produtividade dos frutos de quiabeiro da cultivar Santa Cruz em função de diferentes doses de esterco bovino e adubação mineral.

Esse resultado demonstra que a adubação orgânica foi eficiente no fornecimento de nutrientes para a cultura, conseguindo alcançar efeito similar à adubação mineral, o que ajuda a esclarecer a ausência da diferença estatística entre os tratamentos. De certo beneficiando os agricultores com a alternativa de substituir os fertilizantes minerais com intuito de reduzir os custos da atividade produtiva e contribuir com a sustentabilidade do sistema de produção.

\section{CONCLUSÕES}

Nas condições edafoclimáticas do presente estudo a adubação utilizando o esterco bovino proporciona bom incremento na produtividade de quiabos. Faz-se necessário novos estudos com a aplicação de doses superiores de esterco bovino, a fim de se determinar a produtividade máxima de frutos de quiabo.

\section{REFERÊNCIAS}

ALVAREZ, V.; NOVAIS, R. F.; BARROS, N. F.. Interpretação dos resultados das análises de solos. In: RIBEIRO, A. C.; GUIMARÃES, P. T. G.; ALVAREZ V. V. H.. Recomendações para o uso de corretivos e fertilizantes em Minas Gerai $5^{\text {a }}$ aproximação. Viçosa: Comissão de Fertilidade do Solo do Estado de Minas Gerais, 1999. p.25-32.

ANDRADE, L. H. N. T.; NUNES, M. U. C.. Produtos alternativos para o controle de doenças e pragas em agricultura orgânica. Embrapa, Tabuleiros Costeiros, 2001.

ARAUJO, A. S.; SILVA, J. E. C; SANTOS, A. C.; SILVA NETO, S. P.; DIM, V. P.; ALEXANDRINO, E.. Substituição de nitrogênio por esterco bovino na produtividade de forragem $\mathrm{e}$ qualidade do solo. Revista Brasileira de Saúde Produção Animal, Salvador, v.12, n.4, p.852-866, 2011.

ARAUJO, L. C.; SANTOS, A. C.; FERREIRA, E. M.; CUNHA, O. F. R.. Fontes de matéria orgânica como alternativa na melhoria das características químicas do solo e produtividade do capim-mombaça. Revista Acadêmica Ciências Agrárias e Ambientais, Curitiba, v.6, n.1, p.65-72, 2008. DOI: http://doi.org/10.7213/cienciaanimal.v6i1.10358

BASSO, S. M. S.; SCHERER, C. V.; ELLWANGER, M. F.. Resposta de pastagens perenes à adubação com chorume suíno: pastagem natural. Revista Brasileira de Zootecnia, Viçosa, v.37, n.2, p.221-227, 2008. DOI: http://doi.org/10.1590/S1516-35982008000200007 
FILGUEIRA, F. A. R.. Novo manual de olericultura: agrotecnologia moderna na produção e comercialização de hortaliças. 2 ed. Viçosa: UFV, 2008.

PEIXOTO FILHO, J. U.; FREIRE, M. B. G. S.; FREIRE, F. J.; MIRANDA, M. F. A.; PESSOA, L. G. M.; KAMIMURA, K. M.. Produtividade de alface com doses de esterco de frango, bovino e ovino em cultivos sucessivos. Revista Brasileira Engenharia Agrícola e Ambiental, Campina Grande, v.17, n.4, p.419-424, 2013. DOI: http://dx.doi.org/10.1590/S1415$\underline{43662013000400010}$

IBGE. Instituto Brasileiro de Geografia e Estatística. Senso Agropecuário 2006: Brasil, Grandes Regiões e Unidades da Federação. Rio de Janeiro: IBGE, 2006.

KHATOUNIAN, C. A.. A reconstrução ecológica da agricultura. Botucatu: Agroecológica, 2001.

LINHARES, P. C.; PEREIRA, M. F. S.; MOREIRA, J. C.; PAIVA, A. C. C.; ASSIS, J. P.; SOUSA, R. P.. Rendimento do coentro (Coriandrum sativum $\mathrm{L}$ ) adubado com esterco bovino em diferentes doses e tempos de incorporação no solo. Revista Brasileira de Plantas Medicinais, Campinas, v.17, n.3, p.462467, 2015. DOI: http://dx.doi.org/10.1590/1983

OLIVEIRA, A. P.; ALVES, A. U.; DORNELAS, C. S. M.; SILVA, J. A. S.; PÔRTO, L. M.; ALVES, A. U.. Rendimento de quiabo em função de doses de nitrogênio. Acta Scientiarum. Agronomy, Maringá, v.25, n.2, p.265-268, 2003. DOI: http://doi.org/10.4025/actasciagron.v25i2.1761

OLIVEIRA, A. P.; SANTOS, J. F.; CAVALCANTE, F. L.; PEREIRA, W.; SANTOS, M. C. C. A.; OLIVEIRA, A. N. P.; SILVA, N. S.. Yield of sweet potato fertilized with cattle manure and biofertilizer. Horticultura Brasileira, Brasília, v.28, n.3, p.277281, 2010. DOI: http://doi.org/10.1590/\$010205362010000300006

PES, L. Z.; ARENHARDT, M. H.. Fisiologia vegetal. Universidade Federal de Santa Maria. Rede e-Tec Brasil, 2015.
SABITHA, V.; RAMACHANDRAN, S.; NAVEEN, K. R.; PANNEERSELVAM, K.. Antidiabet

AntidiabeticandantihyperlipidemicpotentialofAbelmoschuse sculentus (L.) Moenchinstreptozotocin-induceddiabeticrats. Journal Pharm Bioallied Sci,. v.3, n.3, p.397-02, 2011.

SANTOS, H. G.. Sistema brasileiro de classificação de solos. 3 ed. Brasília: Embrapa, 2013

SANTOS, J. F.; OLIVEIRA, A. P.; ALVES, A. U.; BRITO, C. B.; DORNELAS, C. S. M.; NÓBREGA, J. P. R.. Produção de batatadoce adubada com esterco bovino em solo com baixo teor de matéria orgânica. Horticultura Brasileira, Vitória da Conquista, v.24, n.1, p.103-106, 2006. DOI: https://doi.org/10.1590/S0102-05362006000100021

SILVA, J. A.; ARAÚJO, A. E. S.; ARAÚJO, M. A. M.; SILVA, J. A; OLIVEIRA, F. J. M; NUNES, J. C.; CARVALHO, R. O.

Componentes produtivo do quiabeiro adubado com esterco bovino e biofertilizante. Horticultura Brasileira, v.30, n.2, p.S5419-S5424, 2012.

SOUZA, I. M.; SOUZA, J. A. M.; ALVES, J. D. N.; PIRES, E. S.; CORDEIRO, R. A. M.. Avaliação da produção de mudas de quiabeiro em estufa com diferentes substratos orgânicos. Nucleus, v.11, n.1, 2014. DOI: http://doi.org/10.3738/1982.2278.1051

SOUSA, A. P. B.; LIMA, F. G. S.; LIMA, A.. Propriedades nutricionais do Maxixe e do Quiabo. Revista Saúde em foco, Teresina, v.2, n.1, p.113-129, 2015.

TIVELLI, S. W.; KANO, C.; PURQUERIO, K. L. F. V.; WUTKE, E. B.; ISHMURA, I.. Desempenho do quiabeiro consorciado com adubos verdes eretos de porte baixo em dois sistemas de cultivo. Horticultura Brasileira, Vitória da Conquista, v.31, n.3, 2013. DOI: https://doi.org/10.1590/S0102$\underline{05362013000300023}$

TRANI, P. E.; TERRA, M. M.; TECCHIO, M. A.; TEIXEIRA, L. A. J.; HANASIRO, J.. Adubação orgânica de hortaliças e frutíferas. Uberlândia: Campo Negócios HF, 2008.

TAIZ, L.; ZEIGER, E.. Fisiologia vegetal. 3 ed. Porto Alegre: ARTMED, 2004.

A CBPC - Companhia Brasileira de Produção Científica (CNPJ: 11.221.422/0001-03) detém os direitos materiais desta publicação. Os direitos referem-se à publicação do trabalho em qualquer parte do mundo, incluindo os direitos às renovações, expansões e disseminações da contribuição, bem como outros direitos subsidiários. Todos os trabalhos publicados eletronicamente poderão posteriormente ser publicados em coletâneas impressas sob coordenação da Sustenere Publishing, da Companhia Brasileira de Produção Científica e seus parceiros autorizados. Os (as) autores (as) preservam os direitos autorais, mas não têm permissão para a publicação da contribuição em outro meio, impresso ou digital, em português ou em tradução. 